\title{
Clinical Parameters and its Association with Coronary Involvement in Diabetic vs. Non-Diabetic CAD Patients with Reference to SYNTAX Score
}

Tejas Shah*

Department of Cardiology, Sumandeep Vidyapeeth, Vadodara, Gujarat, India

*Author for correspondence:

Tejas Shah, Department of Cardiology, Sumandeep Vidyapeeth, Vadodara, Gujarat India, Tel: +91 8951274202 ,

E-mail: tejaschaitri@gmail.com

Materials and methodology: 200 patients (100 Diabetics and 100 Non diabetics) after meeting inclusion and exclusion criteria, admitted with symptoms of acute or chronic coronary syndrome, scheduled to undergo coronary angiogram were taken.

Results: In our study duration of diabetes and severity of coronary artery disease was not correlating but as compared to non-diabetics, diabetics had higher SYNTAX score between 23-32 30(30\%) were diabetics, while 13(13\%)were nondiabetics, and score $>33$ 9, (9\%) were diabetics as compared to 1(1\%) nondiabetic, p value $<0.001$. Diabetics have more numbers of TVD (Triple Vessel Disease) $52 \%$ as compared to Nondiabetics $12 \%$, p value $<0.001$. Diabetics had more numbers of Total occlusion of vessel $(p=0.027)$, Calcification $(p=0.003)$, Proximal vessel involvement, $(p=0.000)$ CTO (chronic total occlusion), $p=0.027$ and diffusely disease vessels $(p=0.000$ ), as compared to nondiabetics. Biochemical parameters like FBS, $\mathrm{HbA1c}$ and clinical parameters like BMI and Hypertension were not correlating with severity of coronary artery disease. In controls age is highly correlated with severity of coronary artery disease with correlation coefficient of 0.363 ( $p$ value $=0.0001$ ) whereas in cases TC/HDL is highly correlated with severity of coronary artery disease with correlation coefficient of 0.205 ( $p$ value 0.041 ).

Conclusion: Diabetics have more numbers of Total vessel occlusion, CTOs, proximal vessel involvement, calcifications and diffuse CAD.TC/HDL is better parameter to predict severity of CAD.

Keywords: Coronary Artery Disease $n$ SYNTAX scor Chronic Total Occlusion (CTO)

Introduction: Globally, People with diabetes have increased alarmingly since 1985 and the rate of new cases is by 2003 was approximately 194 million people, which will increase to almost 350 million by 2025 [1]. Diabetes mellitus is a very strong risk factor the development of CHD and stroke [2]. In diabetics the incidence and severity of microvascular disease (nephropathy, retinopathy, neuropathy, and peripheral small vessel disease) are directly related to the duration and severity of hyperglycemia and macrovascular disease (coronary, cerebrovascular and peripheral vascular) is related to insulin resistence and hyper insulinemia with diffuse vessel involvement [3-6]. In non-diabetic patients besides hypercholesterolemia, increasing number of components of the metabolic syndrome was shown to be significantly correlated to the severity of coronary artery disease. Increased concentrations of triglyceride-rich VLDL particles contribute to abnormal HDL metabolism in insulin resistance, which causes premature atherosclerosis and death in diabetic patients [7-10].

Diabetics experience higher mortality and morbidity after Acute Coronary Syndrome (ACS) and Myocardial Infraction (MI) than people without diabetes [11]. Recent evidence has indicated that chronic severe hyperglycemia and a long duration of the disease both enhance the risk of fatal and nonfatal ischemic events [12-14]. It induces nonenzymatic glycation of proteins and lipids resulting in increased AGEs (Advance Glycated End products) formation $[15,16]$. Another hypothesis in diabetics is endothelial dysfunction as the central initiating factor of the increased atherosclerosis which have been associated with an increased risk of CVD $[17,18]$

Studies have shown that patients with diabetes more frequently have left main coronary artery lesions, multi vessel disease which is more severe and diffuse as well as more calcified and complicated lesions [19]. Diabetics exhibited more complicated atherosclerotic plaques with ulcer, thrombosis and hemorrhages. 


\section{Materials and Method}

This was a single center, case control study conducted at tertiary care hospital attached with medical college. Sample size was calculated as per the following formula. $\mathrm{N}=2\left(\mathrm{z}_{\alpha}+\mathrm{z}_{\beta}\right) \sigma^{2} / \mathrm{d}^{2} .200$ Asian Indian patients (100 cases and 100 controls) after meeting the inclusion and exclusion criteria and scheduled to undergo CAG were enrolled.

Cases were diabetics with age between (35-70 years), who were taking biguanides, sulphonylureas or alpha-glucosidase inhibitors. While controls were Non diabetics with same age groups were taken. Patients were not on antiplatelets, statins, B-blockers, ACE inhibitors, ARB or Nitrates. Hypertensive patients were on alpha blockers, central sympatholytics, vasodilators or diuretics group of drugs. Coronary angiography was performed after diagnosing coronary syndrome in cases and controls. Patients with Type I diabetes, Pregnant female, CKD (chronic kidney disease), family and past history of IHD and age $>70$ years were excluded.

\section{Methods}

The study was conducted after obtaining approval from the Institutional Ethical Committee. After written informed consent, detailed history was taken from all patients scheduled to undergo coronary angiogram, admitted with symptoms of ischemic heart disease. Following biochemical and clinical assay was carried out.

1) Anthropometric Parameters: Height weight and BMI (kg/mt2) was measured according to WHO norms [20].

Waist Circumference: For the Asian Indians [21]. Normal Values:

1. Males: $<90 \mathrm{~cm}$ as normal and $>90 \mathrm{~cm}$ as having central obesity.

2. Females: $<80 \mathrm{~cm}$ as normal and $>80 \mathrm{~cm}$ as having central obesity

2) Fasting Lipid Profile: The serum (venous blood) is separated and analysed using Hitachi P 800 auto analyser. Values were considered normal according to our laboratory reference values.

Total Cholesterol (TC), Normal Value: $<200 \mathrm{mg} / \mathrm{dl}$

HDL Cholesterol (HDL-C), Normal Value: $\geq 40 \mathrm{mg} / \mathrm{dl}$

Triglycerides: Normal values- $<150 \mathrm{mg} / \mathrm{dl}$.

LDL Cholesterol (LDL-C): it is calculated using the following formula

LDL-C=[Total Cholesterol - (HDL-C+VLDL-C) $]$

VLDL-C=Serum Triglycerides $/ 5 \mathrm{mg} / \mathrm{dl}$

Normal Value: Upto $100 \mathrm{mg} / \mathrm{dl}$.

Ratio of Total cholesterol to HDL-C, Normal: 3.5-5

3) Fasting Glucose: The plasma (venous blood) is separated and analysed using Hitachi P800 auto analyser. The estimation of glucose is based on GOD-POD method. Reference Value: <126 $\mathrm{mg} / \mathrm{dl}$.
4) HbA1c: HbA1c is analysed by affinity chromatography.

Reference Value: $<6.5$

5) Severity of ischemic heart disease: severity of ischemic heart disease will be assessed by SYNTAX scoring system. It is calculated with help of online CARDI $\infty$ LYSIS, Boston Scientific, online 2.11 calculator.

\section{Key angiographic features [22]}

Right or left dominant system

Number of artery segments involved per atherosclerotic lesion.

Total occlusion:

Number of segments involved

Age of total occlusion

Presence of blunt stump

Presence of bridging collaterals

Antegrade vs. retrograde filling of the first segment beyond the occlusion.

Side branch involvement

- Trifurcation lesion: number of vessel segments diseased

- Bifurcation lesion: angulation between the distal main vessel and the side branch $<700$

- Presence of an aorto-ostial atherosclerotic lesion

Presence of severe vessel tortuosity at lesion site

- Atherosclerotic lesion length>20 mm

- Presence of heavily calcified plaque

- Presence of thrombuss

- Presence of diffuse or small vessel disease

Scoring was graded between 0-22, 23-32, >33.

\section{Statistical analysis}

Statistical analysis was performed using SPSS. Data were summarized using descriptive statistics, presented as proportions $(\%$, count/sample size) or mean $\pm \mathrm{SD}$. Continuous variables were compared with the use of the student $t$ test; differences in discrete variables were assessed by means of the chi-square test or Fisher exact test, as appropriate. Pearson coefficient of correlation was used to analyze correlation between outcome variables. $\mathrm{p}$ value of $<0.05$ will be taken as significant. 
Research Article

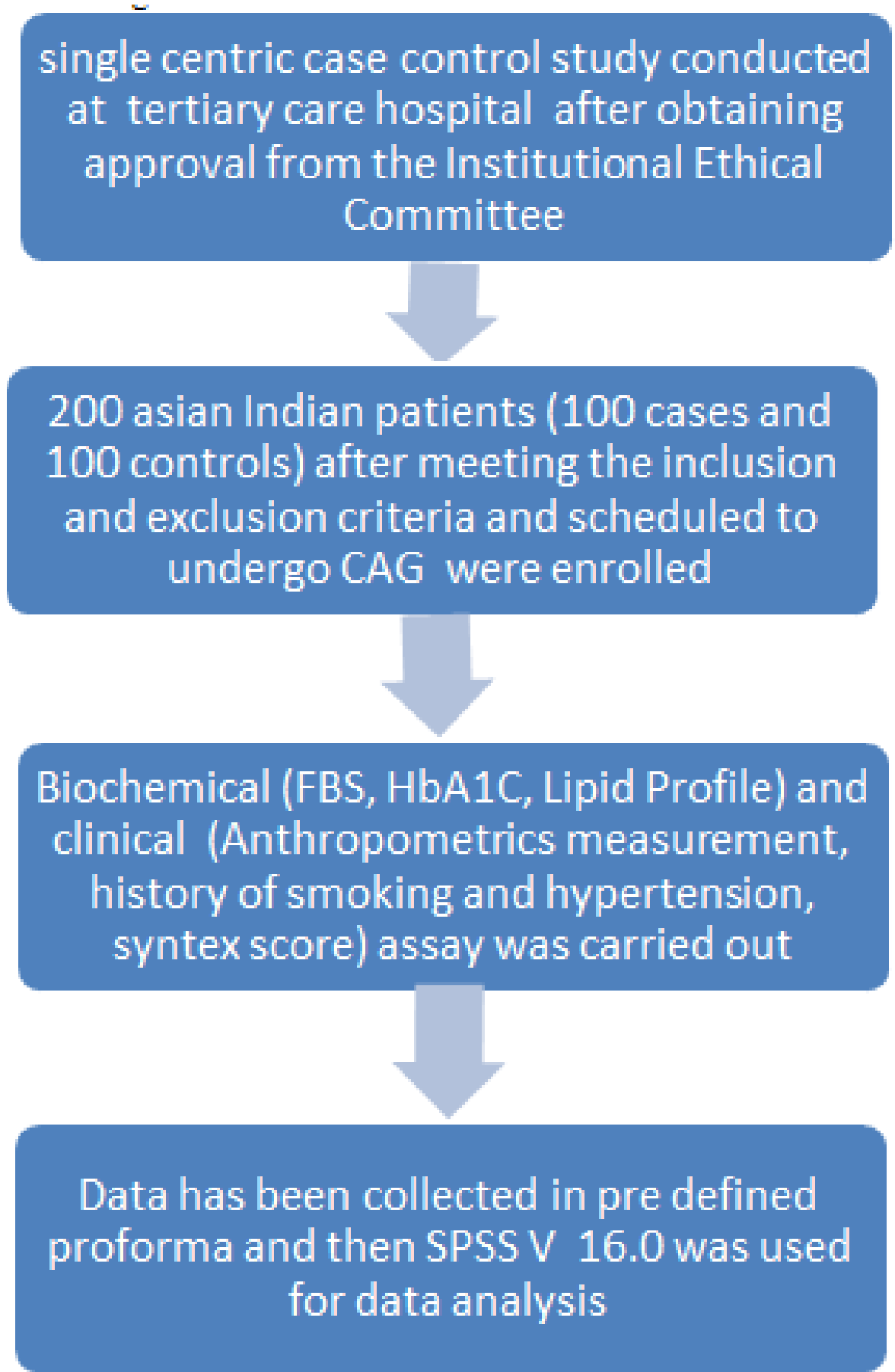

\section{Observation and Results}

The present study was conducted in tertiary care center. 200 patients, 100 cases and 100 controls were taken. Following observations were made from study (Tables 1-6). 
Research Article

\begin{tabular}{|c|c|c|c|c|c|c|}
\hline Variable & $\mathbf{N}$ & Cases Mean \pm SD & Control Mean \pm SD & Average & $t$ value & p value \\
\hline Age & 200 & $58.51 \pm 8.95$ & $56.91 \pm 9.37$ & $57.71 \pm 9.18$ & 1.234 & 0.219 \\
\hline Wt & 200 & $64.83 \pm 12.65$ & $64.37 \pm 12.25$ & $64.60 \pm 12.42$ & 0.264 & 0.792 \\
\hline BMI & 200 & $25.20 \pm 4.17$ & $23.55 \pm 3.72$ & $24.37 \pm 4.03$ & 2.949 & 0.004 \\
\hline WC & 200 & $35.42 \pm 4.43$ & $34.22 \pm 4.92$ & $34.82 \pm 4.71$ & 1.816 & 0.071 \\
\hline FBS & 200 & $189.35 \pm 72.01$ & $111.69 \pm 34.40$ & $150.52 \pm 68.44$ & 9.731 & 0.001 \\
\hline $\mathrm{HbA1C}$ & 200 & $9.00 \pm 1.70$ & $5.92 \pm 1.12$ & $7.46 \pm 2.11$ & 15.192 & 0.001 \\
\hline $\mathrm{TC}$ & 200 & $183.20 \pm 58.59$ & $183.37 \pm 47.50$ & $183.29 \pm 53.20$ & 0.023 & 0.982 \\
\hline LDL & 200 & $118.17 \pm 50.28$ & $116.18 \pm 40.43$ & $117.17 \pm 45.52$ & 0.308 & 0.758 \\
\hline $\mathrm{HDL}$ & 200 & $41.83 \pm 12.84$ & $42.64 \pm 12.66$ & $42.23 \pm 12.73$ & 0.450 & 0.653 \\
\hline Score & 200 & $18.77 \pm 9.72$ & $13.16 \pm 8.01$ & $15.97 \pm 9.32$ & 4.454 & 0.001 \\
\hline TG & 200 & $128.29 \pm 57.61$ & $117.95 \pm 65.66$ & $123.12 \pm 61.83$ & 1.184 & 0.238 \\
\hline $\mathrm{TC} / \mathrm{HDL}$ & 200 & $4.67 \pm 1.61$ & $4.60 \pm 1.73$ & $4.63 \pm 1.67$ & 0.286 & 0.775 \\
\hline
\end{tabular}

\begin{tabular}{|c|c|c|c|c|c|}
\hline Variable & Variable & Variable & Variable & Variable & Variable \\
\hline Domain*Group & 0.190 & 0.663 & & & \\
\hline Total occlusion*Group & 4.878 & 0.027 & Sig & & \\
\hline Trifurcation*Group & 4.421 & 0.036 & Sig & & \\
\hline Bifurcation*Group & 3.366 & 0.067 & & & \\
\hline Medina*Group & 2.854 & 0.091 & & & \\
\hline Angulation $<70^{*}$ Group & 2.537 & 0.111 & & & \\
\hline $\begin{array}{c}\text { Severe Tortuosity * } \\
\text { Group }\end{array}$ & 4.735 & 0.030 & Sig & & \\
\hline Length $>20 *$ Group & 3.720 & 0.054 & & & \\
\hline Calcification*Group & 8.589 & 0.003 & HS & & \\
\hline Thrombus*Group & 5.227 & 0.022 & Sig & & \\
\hline $\begin{array}{c}\text { Diffusely } \\
\text { Disease*Group }\end{array}$ & 24.669 & 0.000 & HS & & \\
\hline Aortoostial*Group & 2.083 & 0.149 & & & \\
\hline Proximal*Group & 48.256 & 0.000 & HS & & \\
\hline СTO*Group & 4.880 & 0.027 & Sig & & \\
\hline Leftmain*Group & 2.55 & 0.614 & & & \\
\hline Score*Group & & & & 0.000 & HS \\
\hline Involvement*Group & & & & 0.000 & $\mathrm{HS}$ \\
\hline
\end{tabular}


Research Article

Table 3: Charts showing comparison between cases and control for involvement of vessels (Normal, Single vessel d"s, Double vessel d"s, Triple Vessel d"s.).

\begin{tabular}{|c|c|c|c|}
\hline Involvement & Cases N (\%) & Control N (\%) & Total N (\%) \\
\hline Single Vessel Disease (SVD) & $17(17.00 \%)$ & $37(37.00 \%)$ & $54(27.00 \%)$ \\
\hline Double Vessel Disease (DVD) & $31(31.00 \%)$ & $46(46.00 \%)$ & $77(38.50 \%)$ \\
\hline Triple Vessel Disease (TVD) & $52(52.00 \%)$ & $12(12.00 \%)$ & $64(32.00 \%)$ \\
\hline Normal & $0(0.00 \%)$ & $03(03.00 \%)$ & $3(1.50 \%)$ \\
\hline Other & $0(0.00 \%)$ & $02(2.00 \%)$ & $2(1.00 \%)$ \\
\hline Total & $100(100.00 \%)$ & $100(100.00 \%)$ & $200(100.00 \%)$ \\
\hline
\end{tabular}

Table 4: Chart comparing SYNTAX score among cases and control (Total score).

\begin{tabular}{|c|c|c|c|}
\hline $\begin{array}{c}\text { Table 4: Chart comparing SYNTAX score among cases and control (Total score). } \\
\text { SYNTAX Score }\end{array}$ & Cases N (\%) & Control N (\%) & Total N (\%) \\
\hline $0-22$ & $61(61.00 \%)$ & $86(86.00 \%)$ & $147(73.50 \%)$ \\
\hline $23-32$ & $30(30.00 \%)$ & $13(13.00 \%)$ & $43(21.50 \%)$ \\
\hline$\geq 33$ & $9(09.00 \%)$ & $1(01.00 \%)$ & $10(05.00 \%)$ \\
\hline Total & $100(100.00 \%)$ & $100(100.00 \%)$ & $200(100.00 \%)$ \\
\hline
\end{tabular}

\section{Table 5: Chart showing duration of diabetes and severity of score.}

\begin{tabular}{|c|c|c|c|c|}
\hline \multirow{2}{*}{ DM Duration } & \multicolumn{3}{|c|}{ SYNTAX Score } & \multirow{2}{*}{ Total N (\%) } \\
\cline { 2 - 4 } & $\mathbf{0 - 2 2}$ & $\mathbf{2 3 - 3 2}$ & $\mathbf{3 3}$ & \multirow{2}{*}{$10(10.00 \%)$} \\
\hline$<1$ Years & $5(50.00 \%)$ & $5(50.00 \%)$ & $0(00.00 \%)$ & $24(24.00 \%)$ \\
\hline $1-5$ Years & $17(70.8 \%)$ & $7(29.2 \%)$ & $0(00.00 \%)$ & $17(17.00 \%)$ \\
\hline $5-10$ Years & $11(64.70 \%)$ & $4(23.50 \%)$ & $2(11.80 \%)$ & $49(49.00 \%)$ \\
\hline$\geq 10$ Years & $27(55.10 \%)$ & $21(42.90 \%)$ & $1(02.00 \%)$ & $100(100.00 \%)$ \\
\hline Total & $60(60.00 \%)$ & $37(37.00 \%)$ & $3(03.00 \%)$ & \\
\hline
\end{tabular}

\section{Table 6: Chart showing various parameters with its correlation with seventy of score.}

\begin{tabular}{|c|c|c|c|c|}
\hline \multirow{2}{*}{ Variable } & \multicolumn{2}{|c|}{ Controls } & \multicolumn{2}{c|}{ Cases } \\
\cline { 2 - 5 } & Pearson Correlation & p value & Pearson Correlation & p value \\
\hline Age & 0.363 & 0.000 & 0.052 & 0.606 \\
\hline BMI & -0.073 & 0.472 & 0.025 & 0.802 \\
\hline Smoking & -0.096 & 0.341 & 0.099 & 0.326 \\
\hline HTN & -0.070 & 0.491 & 0.035 & 0.728 \\
\hline FBS & 0.016 & 0.877 & 0.113 & 0.262 \\
\hline HbA1C & -0.028 & 0.780 & 0.114 & 0.260 \\
\hline TC & 0.051 & 0.613 & 0.040 & 0.691 \\
\hline LDL & 0.075 & 0.461 & 0.035 & 0.726 \\
\hline HDL & 0.088 & 0.384 & -0.143 & 0.155 \\
\hline TG & -0.180 & 0.072 & -0.015 & 0.881 \\
\hline TC/HDL & -0.072 & 0.478 & 0.205 & 0.041 \\
\hline
\end{tabular}


Mean age in cases was 58.51 with standard deviation of 8.95 , while in control it was 56.91 with standard deviation of 9.37. which was statistically not significant ( $\mathrm{p}$ value 0.219 ). Mean weight of cases was 64.83 with standard deviation of 12.65 , while in control it was 64.37 with standard deviation of 12.25 , which was statistically not significant ( $p$ value 0.792 ). As regards to gender distribution of the study population, most of the patients were male 69(69\%) in cases and $82(82 \%)$ in controls. In cases $31(31 \%)$ were female, while in controls $18(18 \%)$. p value was significant $(\mathrm{p}=0.033)$.

Mean BMI was 25.20 in cases with standard deviation of 4.17, while in control it was 23.55 with standard deviation 3.72 which was statistically significant ( $p$ value $=0.004)$. Mean waist circumference was 35.42 with standard deviation of 4.43 in cases, while for control 34.22 with standard deviation of 4.92 . Which was statistically insignificant $(\mathrm{p}=0.07)$. Mean FBS in cases was $189.35 \mathrm{mg} / \mathrm{dl}$ with standard deviation of $72.01 \mathrm{mg} / \mathrm{dl}$, while in control it was $111.69 \mathrm{mg} / \mathrm{dl}$ with standard deviation $34.40 \mathrm{mg} /$ dl. $\mathrm{p}$ value was highly significant $(\mathrm{p}=0.000)$. Mean HbAlc Value in case was 9 with standard deviation of 1.70 , while in control it was 5.92 with standard deviation of 1.12 . P value was highly significant $(p=0.000)$. Mean value of Total cholesterol was 183.20 $\mathrm{mg} / \mathrm{dl}$ with standard deviation of 58.59 in cases, while in controls it was $183.37 \mathrm{mg} / \mathrm{dl}$ with standard deviation of 47.50 . P value was statistically not significant $(\mathrm{p}=0.982)$. Mean value for Low Density Lipoprotien-cholesterol (LDL-C) was $118.17 \mathrm{mg} / \mathrm{dl}$ for cases with standard deviation of 50.28 , while in control it was $116.18 \mathrm{mg} /$ $\mathrm{dl}$ with standard deviation of 40.43 . $\mathrm{p}$ value was not significant $(\mathrm{p}=0.758)$.

Mean value for High density Lipoprotein-cholesterol (HDL-C) was $41.83 \mathrm{mg} / \mathrm{dl}$ in cases with standard deviation was 12.84 , while controls having $42.64 \mathrm{mg} / \mathrm{dl}$ and standard deviation of 12.66. $\mathrm{p}$ value was statistically not significant $(\mathrm{p}=0.653)$.

Mean value of triglycerides in cases was $128.29 \mathrm{mg} / \mathrm{dl}$ with standard deviation of $57.61 \mathrm{mg} / \mathrm{dl}$, while in controls it was 117.95 $\mathrm{mg} / \mathrm{dl}$ with standard deviation of $65.66 \mathrm{mg} / \mathrm{dl}$. p value was not significant $(p=0.238)$. Mean value for TC/HDL ratio in cases was 4.67 with standard deviation of 1.61 , while for control it was 4.60 with standard deviation of 1.73 . $p$ value was not significant $(\mathrm{p}=0.775)$.

Mean value of SYNTAX score in cases 18.77 with standard deviation 9.72, while in control 13.16 with standard deviation 8.01. $\mathrm{p}$ value was highly significant $(\mathrm{p}=0.00)$.

In 100 patient with diabetes $60(60 \%)$ had right dominance system, while $40(40 \%)$ had left dominance system. In control 63 (63\%) had right dominance, while 37 (37\%) had left dominant system. $\mathrm{p}$ value was not significant $(\mathrm{p}=0.663)$.

Out of 100 cases 24 (24\%) had Total occlusion of vessel, while in control $12(12 \%)$ had Total occlusion of vessel. $p$ value was significant $(\mathrm{p}=0.027) .8(8 \%)$ of cases had trifurcation lesion, while $18(18 \%)$ of control had trifurcation lesion. p value was significant $(\mathrm{p}=0.036) .37(37 \%)$ of cases had bifurcation lesion, while $25(25 \%)$ of control had bifurcation lesions. p value was not significant $(\mathrm{p}=0.067) .32(32 \%)$ of cases had vessel angulation in bifurcation lesion $<70^{\circ}$, while $22(22 \%)$ of control had Angulation in bifurcation lesion $<70^{\circ}$. $p$ value was not significant $(\mathrm{p}=0.111) .7$ $(7 \%)$ of cases had severe tortuosity, while $17(17 \%)$ of control had severe tortuosity. $p$ value was significant $(p=0.030) .21(21 \%)$ of cases had a lesion length>20 mm, while $11(11 \%)$ of controls had lesion length $>20 \mathrm{~mm}$. p value was not significant. $(\mathrm{p}=0.054) .23$ $(23 \%)$ of cases had calcification in lesion, while $8(8 \%)$ of control had calcification in lesion. $\mathrm{p}$ value was highly significant. $(p=0.003) .18(18 \%)$ cases had thrombus in vessel, while $32(32 \%)$ of control had thrombus. $p$ value was significant. $(p=0.022) .42$ (42\%) cases had diffuse disease, while $11(11 \%)$ of controls had diffuse disease. $p$ value was highly significant. $(\mathrm{p}=0.00) .6(6 \%)$ of cases had aorto-ostial involvement, while $2(2 \%)$ of control had aorto-ostial involvement. $p$ value was not significant $(\mathrm{p}=0.149) .71$ (71\%) of cases had proximal vessel involvement, while 22 (22\%) of control had proximal vessel involvement. $\mathrm{p}$ value was highly significant $(\mathrm{p}=0.00)$.

$20(20 \%)$ of cases had Chronic Total Occlusion (CTO), while $9(9 \%)$ of control had CTO.p value was significant. $(\mathrm{p}=0.027) 3$ $(3 \%)$ of cases had left main involvement, while $1(1 \%)$ of control had left main involvement. $p$ value was not significant $(\mathrm{p}=0.614)$.

Out of 100 cases majority patient $52(52 \%)$ had Triple vessel disease (TVD), 31 (31\%) had double vessel disease (DVD) and $17(17 \%)$ had Single vessel disease (SVD). While in control majority 46 (46\%) had Double vessel disease (DVD); followed by $37(37 \%)$ had Single vessel disease (SVD); 12 (12\%) had Triple vessel disease (TVD). 3(3\%) had Normal coronaries out of $2(2 \%)$; 1 had minor CAD, other had recanalized Vessel. p value was highly significant ( $\mathrm{p}$ value $=0.00)$.

Out of 100 cases 61 (61\%) patients had score in between 0-22; while $30(30 \%)$ had score in between $23-32$ and $9(9 \%)$ had score above 33.In control $86(86 \%)$ had score between $0-22$, 14 (14\%) had score in between 23-32. While 1(1\%) had score>33. p value was highly significant $(\mathrm{p}=0.00)$.

Diabetic patients were divided according to duration of disease $<1$ year, 1 to 5 year; 5 to 10 year and more than 10 years, which was compared with score $<22 ; 22-32$ and $>33$.

Results showed that majority of patients had duration of diabetes 10 years and above, out of 49 cases, 27 had score between $0-22,21$ had score between 23-32,1 had score $>33$. Diabetes of $<1$ year duration, 10 out of 5 had score $<22$, remaining had between 2332. Those who had 1 to 5 years duration of diabetes, out of 24 , 17 had score $<22$, while 7 had in between 23-32.In 5-10 year of diabetes duration, out of 17 patient 11 had score $<22,4$ had score 23-32; 2 had score $>33$. As duration of diabetes has increased score has increased but, $\mathrm{p}$ value for this is not statistically significant $(\mathrm{p}=0.287)$. 
Patients in control group, age was significantly associated with severity of SYNTAX score. p value of 0.000 , while it was not correlating with cases. Body Mass Index (BMI) in cases and control was not correlating with severity of SYNTAX score, $p$ value 0.472 in control, $\mathrm{p}=0.802$ cases. Smoking and Hypertension were not correlating with severity of SYNTAX score in cases and controls, $\mathrm{p}=0.326, \mathrm{p}=0.72$ for cases and $\mathrm{p}=0.341, \mathrm{p}=0.491$ for controls respectively. Fasting blood sugar was not correlating with severity of SYNTAX score in both cases and control group, with p value 0.262 , and p value 0.87 respectively. Body Mass Index (BMI) in cases and control was not correlating with severity of SYNTAX score, $\mathrm{p}$ value 0.472 in control, $\mathrm{p}=0.802$ cases. Smoking and Hypertension were not correlating with severity of SYNTAX score in cases and controls, $\mathrm{p}=0.326, \mathrm{p}=0.72$ for cases and $\mathrm{p}=0.341$, $\mathrm{p}=0.491$ for controls respectively. Fasting blood sugar was not correlating with severity of SYNTAX score in both cases and control group, with $\mathrm{p}$ value 0.262 , and $\mathrm{p}$ value 0.87 respectively. Glycosylated $\mathrm{Hb}$ (HbAlc) was not correlating with the severity of SYNTAX score in cases and control with $p$ value $=0.26$ in cases and $\mathrm{p}$ value 0.780 in control. Total cholesterol; Low density lipoprotein (LDL), High density lipoprotein (HDL) and Triglyceride were not correlating with severity of SYNTAX score in cases and control. $\mathrm{p}$ values for cases were $0.6,0.7,0.1,0.8$, while for control $\mathrm{p}$ values were $0.6,0.4,0.3$, and 0.07 respectively.

TC/HDL ratio was statistically significantly correlating with severity of SYNTAX score in cases; $\mathrm{p}$ value was 0.04 , while in control it was not correlating.

\section{Discussion}

In our study except TC: HDL ratio, none of the parameters like BMI, Hypertension, Smoking, and HbA1c were statistically significantly associated with severity of coronary artery disease in diabetic population. Duration of diabetes was not correlating with severity of coronary artery disease. Diabetics had more numbers of TVD, total occlusion of vessel, CTO, proximal vessel involvement, calcification and diffusely diseased vessel as compared to Nondiabetics.

\section{Age}

Data suggest that the incidence of coronary artery disease rises consistently with increasing age and at an age of 60 years; patients have five told increase risk of disease manifestation than at the age of 40 years [23].

In our study we found that majority of patients here between 51 70 years of age. With mean value for cases around 58 year and for control 56 year. More numbers of patients with higher SYNTAX score in the age groups of 50 to 70 years also had more number of DVD and TVD. In a study conducted by Rafaela a drade Penalva et al., they found that mean age was higher in double vessel and triple vessel disease group, as compared to single vessel subgroup [24].

\section{Gender}

Male gender is a recognized risk factor [24,25]. Between ages of 35-55 years, the mortality rates of ischemic heart disease for white women were one-fifth than of white man [24]. After menopause, however the risk is almost equal. In our study we found that there was male preponderance, with statistically significant correlation.

\section{Hypertension}

Epidemiologic studies of treated and untreated hypertensive patients confirmed that there was a gradually increasing incidence of $\mathrm{CAD}$, stroke and cardiovascular mortality as the blood pressure rises above $110 / 75 \mathrm{~mm} \mathrm{hg}[25]$. CAD is much more common in patients with both DM and hypertension than in patients with DM or hypertension alone, and the development of atherosclerosis was found to be accelerated [26,27]. In our study group more number of diabetics had hypertension as compare to nondiadetics. Duration of hypertension was statistically significantly more in diabetic group.

\section{Acute coronary syndrome presentation:}

In the Framingham Heart study, 32\%-42\% of diabetic patients with myocardial infarction had atypical symptoms (dyspnoea, fatigue, confusion,nausea and vomitting) compared to $6 \%-15 \%$ of those patients without diabetes and it was silent $[28,29]$. In our study diabetic patients who presented with coronary syndrome, $23 \%$ had atypical symptoms like presyncope, giddiness, bloating sensation and vomiting.

In cases, who had acute myocardial infarction were $36 \%$, while controls were $53 \%$. $64 \%$ of cases presented with chronic stable Angina, unstable angina or Non ST elevation MI, while in control it was $47(47 \%)$.p value was significant $(\mathrm{p}=0.016)$.

Diabetic patients who presented with acute myocardial infarction had significantly more killip class,LV Dysfunction as compared to non-diabetic, which is correlating with study conducted by keunHo park et al. [30]. In addition it was found that they were more likely to develop a worsening of killip class at admission and a higher incidence of heart failure [31].

\section{Smoking:}

Smoking is risk factor for development of atherosclerosis. The risk of CVD is doubled in patients with diabetes who smoke cigarettes and the benefits of modifying other risk factors are substantially attenuated [32]. Smokers had Triple vessel disease, more number of diffusely diseased vessels and more number of total occlusion in our study [33].

\section{Obesity}

With regard to Body Mass Index (BMI), it was observed that when compared to mean value it was statistically significantly higher in DM in our study. While waist circumference was not higher. Obesity increases risk for development of type 2 diabetes, CHD, stroke, hypertension, and is associated with insulin resistance in 
normoglycemic individuals as well as those with type 2 diabetes [34-36]. The linkage between obesity and diabetes is so strong that some experts have coined a new term to describe it, diabesity $[37,38]$. BMI was not statistically correlating to severity of score in our study.

\section{Dyslipidemia}

Diabetes dyslipidemia refers to atherogenic dyslipidemia occurring in persons with type 2 diabetes and is characterized by the triad of elevated Triglycerides (TG) levels, reduced High density lipoprotein cholesterol (HDL-C) levels and a preponderance of small dense Low-density lipoprotein cholesterol (LDL-C) particles often referred to as "atherogenic dyslipidemia" [39,40]. All of the three components of this atherogenic dyslipidemia triad are associated with atherogenesis and increased CHD risk [41-43].

When compared to non-diabetic in our study population Total cholesterol, Triglyceride, Low Density Lipoprotein and High Density Lipoprotein were not significantly correlating with SYNTAX score, while TC/HDL ratio was statistically significantly correlating with severity of SYNTAX score.

\section{Glycemic control}

Glycated Hemoglobin (HbAlc) reflects the average blood glucose concentrations over the preceding 3 months [44]. Compare with the fasting blood glucose test, HbAlc has several advantages,it has higher repeatability, can be assessed in non-fasting state, and more convenient test with less biological variability and greater stability $[45,46]$. Studies have found an association between elevated cardiovascular risk and elevated $\mathrm{HbAlc}$ level independent of classical risk factor [47]. Chronic hyperglycemia is associated with an increased risk for cardiovascular outcomes and all-cause mortality among patients with type 2 diabetes [48].

However some clinical trials have shown little benefit and possibly some harm, of lowering the glycated hemoglobin value in patients with DM to prevent cardiovascular outcomes [49].

In our study mean value of FBS and HbAlc was statistically highly significant in cases, but it was not correlating with severity of scores.

\section{Angiographic severity}

In diabetics incidence and predominance of CAD is seen even during the stage of impaired glucose tolerance (IGT), which precedes the clinical appearance of diabetes mellitus [50]. It has been reported based on postmortem as well as angiographic studies that CAD in diabetics is more severe and diffuse [51], but there are also studies that contradict this result $[52,53]$.

In our study it has found that as compared to non-diabetic patients, diabetics has significant triple vessel disease, total occlusion of vessels, calcified vessel, and diffuse vessel involvement. In diabetics other parameters like involvement of proximal vessel and chronic total occlusion (CTO) were significantly higher, while in non- diabetics there were more significant trifurcation lesion, severe tortuosity and more thrombus containing lesions.

In terms of SYNTAX score and involvement of vessels (i.e., single vessels, double vessel and triple vessel) it has found that diabetic patient has score $>23-32,>33$ and more of TVD (Triple vessel disease). $p$ value $=0.000$. Multi-vessel disease, involvement of proximal and distal segments in the same vessel, and number of occluded segments, ostial involvement and left main disease in the coronary artery were higher in diabetics [54].

\section{Correlation between severity of CAD and duration of diabetes mellitus:}

Our results showed that there is a no statistically significant correlation between duration of diabetes and severity of CAD, in term of SYNTAX scores ( $p$ value $=0.28$ ). Study performed by A. Natali and Roldano Scognamiglio et al. showed that major risk factors in diabetes like smoking, hypertension, hypercholesterolemia, premature CAD, retinopathy, PVD, HbA1c, and duration of diabetes did not emerge as significant predictors of myocardial perfusion abnormalities or significant CAD.

When duration of DM was compared with pattern of CAD, we observed that it was significantly associated with number of diseased vessels, diseased segments, diffusely diseased vessels, calcification, proximal involvement and total occlusion [55].

\section{Study Limitation}

Our study is a single-center observational experience; patients were only those who underwent coronary angiogram. These patients comprise some patients with $\mathrm{CAD}$ and may not represent all patients with CAD and diabetes mellitus. Substantial information on asymptomatic diabetic patients or those refusing invasive clinical techniques is lacking, when considering increased incidence of painless myocardial infarction among diabetics.

\section{Conclusion}

Conventional risk factors like BMI, Hypertension, Smoking, TC: HDL ratio, and poorly controlled diabetes are strongly associated with coronary artery disease, but in our study except TC: HDL ratio, none of the parameter was statistically significantly associated with severity of coronary artery disease in diabetic population. Duration of diabetes was not correlating with severity of coronary artery disease. Diabetics had more numbers of TVD, total occlusion of vessel, CTO, proximal vessel involvement, calcification and diffusely diseased vessel. Non-diabetics had significant trifurcation lesion, severe tortuosity and more thrombus containing lesions.

\section{Conflict of Interest}

Authors have declared that they have no conflict of interest. 


\section{References}

1. International Diabetes Federation; Diabetes Atlas. $2^{\text {nd }}$ edition, Brussels, Belgium: International Diabetes Federation; 2003.

2. Shah $\mathrm{AD}$, Langenberg $\mathrm{C}$, Rapsomaniki E, et al. Type 2 diabetes and incidence of cardiovascular disease:a cohort study in 1.9 million people. Lancet Diabetes Endocrinol. 2015;3:105-113.

3. Haffer SM, Meittinen H. Insulin resistance implications for type II diabetes mellitus and coronary heart disease. Am J Med. 1997;103:152-162.

4. Koch M, Gradaus F, Schoebel FC, et al. Relevance of conventional Cardiovascular risk factors for the prediction of coronary disease in diabetic patients on renal replacement therapy. Nephrol Dial Transplant. 1997; $12: 1187-1191$

5. Escalante DA, kim DK, Garber AJ, et al. Atherosclerotic Cardiovascular disease. Curr Ther Diab. 1998;176-190.

6. Font bonne A, Eschwerge E, Cambien F, et al. Hypertriglyceridaemia as a risk factor of coronary heart disease mortality in subjects with impaired glucose tolerance or diabetes. Diabetologia. 1989;32:300-304.

7. Nikkila EA, Hormilla P. Serum lipids and lipoproteins in insulin treated diabetes. Demonstration of increased high density lipoprotein concentrations. Diabetes. 1978;27:1078-1086.

8. DeebSS,ZambonA, CarrMC, etal. Hepaticlipaseand dyslipidemia:interactions among genetic variants,obesity,gender and diet. J Lipid Res. 2003;44:12791286

9. Suri RK, Guptha MM, Chakravarthi AK, et al. Hyperlipidaemia and vascular population of diabetes mellitus. J Ass Phys India. 1979;27:505.

10. Reaven GM.Role of insulin resistance in human disease. Diabetes. 1988;37:1595-1607.

11. Low Wang CC, Hess CN, Hiatt WR, et al. Clinical Update:cardiovascular disease in diabetes mellitus:atherosclerotic cardiovascular disease and heart failure in type II diabetes mellitus-mechanisms,managementand clinical considerations.Circulation. 2016;133:2459-2502.

12. Natali A1, Vichi S, Landi P, et al. Coronary atherosclerosis in type II diabetes. Angiographic findings and clinical outcome. Diabetologia. 2000;43:632-641.

13. Scognamiglio R, Negut C, Ramondo A, et al. Detection of coronary artery disease in asymptomatic patients with type 2 diabetes mellitus. J Am Coll Cardiol. 2006;47;65-71.

14. Kataoka Y, Yasuda S, Morii I, et al. Quantitative coronary angiographic studies of patients with angina pectoris and impaired glucose tolerance. Diabetes care. 2005;28:2217-2222.

15. Cooper ME. Importance of advanced glycation end products in diabetes associated cardiovascular and renal disease. Am J Hypertens. 2004;17:31S-38S.

16. Farmer DG, Kennedy S. RAGE,vascular tone and vascular disease. Pharmacol Ther. 2009;124:185-194.

17. Widlansky ME, Gokce N, Keaney JF Jr, et al. The clinical implications of endothelial dysfunction. J Am Coll Cardiol. 2003;42:1149-1160.

18. Corretti MC, Anderson TJ, Benjamin EJ, et al. Guidelines for the ultrasound assessment of endothelial - dependent flow mediated vasodilation of the brachial artery: A report of the International Brachial Artery Reactivity Task Force. J Am Coll Cardiol. 2002;39:257-265.

19. Kappetein AP, Milan Milojevic M, Serruys P, et al. Treatment of Left main coronary artery disease in patients with diabetes:3- year outcomes comparing CABG and PCI with Everolimus- eluting stents from the EXCEL study. JACC cardiovasc interv 2017;69:967.

20. 20.Physical status: The use and interpretation of anthropometry, Geneva: Report of a WHO expert committee, WHO technical report series. 1995;854:324.

21. Longo DL, Fauci AS, Kasper DL, et al. Harrison's :Principle of Internal
Medicine. 18th edition. New York: McGraw Hills,2012;P1992.

22. Capodanno D,Capranzano P, Di Salvo ME, et al. Usefulness of SYNTAX score to select patients with left main coronary artery disease to be treated with coronary bypass graft. JACC cardiovasc interv. 2009;2:731-738.

23. Kumar V, Abbas AK, Fausto N, et al. Pathologic basis of Disease. 7th edition. philadelphia:Elsevier. 2014;P520.

24. Penalva RA, Huoya MO, Correia LC, et al. Lipid profile and severity of Atherosclerotic Disease in Acute coronary syndrome. Arq Bras Cardiol. 2008;90:24-30

25. Pastor Barriuso R ,Banegas JR, Damian J, et al. Systolic Blood pressure, Diastolic Blood pressure, and Pulse pressure: an evaluation of their joint effect on mortality. Ann Intern Med. 2003;139:731-739.

26. Washio M, Sasazuki S, Kodama H, et al. Role of hypertension, dyslipidemia and diabetes mellitus in the development of coronary atherosclerosis in Japan. Jpn Circ J. 2001;65:731-737.

27. Grossman E, Messereli FH. Diabetic and Hypertensive heart disease. Ann Intern Med. 1996;125:304-310.

28. Kannel WB. Lipids, diabetes and coronary heart disease :insights from the Framingham study. Am Heart J. 1985;110:1100-1107.

29. Fox CS,Golden SH,Anderson C, et al. Update on prevention of cardiovascular disease in adults with type 2 diabetes mellitus in light of recent evidence: A scientific statement from the American Heart Association and the American Diabetic Association. Circulation. 2015;132:691-718.

30. Park KH, Ahn Y, Jeong MHo, et al. Different Impact of Diabetes Mellitus on In-hospital and 1-Year Mortality in Patients with Acute Myocardial Infarction Who Underwent Successful Percutaneous Coronary Intervention: Results from the Korean Acute Myocardial Infarction Registry. Korean J Intern Med. 2012;27:180-188.

31. Mak KH, Moliterno DJ, Granger CB, et al. Influence of diabetes mellitus on clinical outcome in the thrombolytic era of acute myocardial infarction: GUSTO- I Investigators. Global utilization of streptokinase and Tissue plasminogen Activator for occluded coronary arteries. J Am coll cordiol. 1997;30:171-179.

32. Grundy SM, Benjamin IJ, Burke GL, et al. Diabetes and cardiovascular disease: a statement for healthcare professionls from the American Heart association. Circulation. 1999; 100:1134-1146

33. David RR, Eric BF, Colin LB et al. Smoking and coronary artery disease assessed by routine coronary arteriography. $\mathrm{Br}$ Med J (Clin Res Ed). 1985;290:197-200

34. Despres JP. The insulin resistance -dyslipidemia syndrome of visceral obesity: effect on patient's risk. Obes Res. 1998;6:85-175.

35. Pi- sunyer Fx. Pathophysiology and long-term management of the metabolic syndrome. Obes Res. 2004;12:1745-1805.

36. Carlsson AC, Riserus U, Arnlov J, et al. Hypertriglyceridemic waist phenotype is associated with decreased insulin sensitivity and incident diabetes in elderly men. Obesity (Silver Spring). 2014;22:526-529.

37. From the NIH: successful diet and exercise therapy is conducted in vermon for "diabesity". JAMA. 1980;243:519-520.

38. Astrup A, Finer N, Redefining type 2 diabetes: "diabesity" or "obesity dependent diabetes mellitus?” (Review).Obes Rev. 2000;1:57-59.

39. Henry N, Ginsberg, Maryam K, et al. Soffer: Diabetes and Dyslipidemia, Endocrinology. Diabetes Complications. Comorbidities and Related Disorders. 2018;2:51-70.

40. Grundy SM. Third Report of the National cholesterol education program (NCEP) expert panel on Detection Evaluation, and Treatment of High blood cholesterol in Adults (Adult Treatment Panel III) Final Report .Circulation. 2002;106:3146-3421.

41. Grandy SM, Cleeman JI, Bairey Merz CN, et al. Implication of recent clinical 


\section{Research Article}

Trials for the National cholesterol education program Adult treatment panel III Guidelines. Circulation. 2004;110:227-239.

42. Austin MA. Plasma triglyceride as a risk factor for cardiovascular disease. Can J cardiol. 1998;14: 14-17.

43. Boden WE. High density lipoprotein cholesterol as an independent risk factor in cardiovascular disease: assessing the date from Framingham to the Veterans Affairs High-Density Lipoprotein intervention Trial. Am J Cardiol. 2000;86:19-22.

44. Selvin E, Crainiceanu CM, Brancati FL, et al. Short term variability in measures of glycaemia and implications for the classification of diabetes. Arch intern Med. 2007;167:1545-1551.

45. Rohlfing C, Wiedmeyer HM, Little R, et al. Biological variation of glycohemoglobin. Clin Chem. 2002;48:1116-1118.

46. Melissa JG. The International Expert committee. International Expert Committee report on the role of the A1c assay in the diagnosis of diabetes. Diabetes Care. 2009;32:1327-1334.

47. Khaw KT, Wareham N. Glycated hemoglobin as a marker of cardiovascular risk. Curr opin Lipidol. 2006;117:637-643.

48. Zhang Y, Hu G, Yuan Z, et al. Glycosylated hemoglobin in relationship to cardiovascular outcomes and death in patients with type 2 diabetes: a systemic review and meta-analysis. Plos One. 2012;7:e 42551.

49. Gerstein HC, Miller ME, Byington RP, et al. The Action to Control
Cardiovascular Risk in Diabetes study group. Effects of intensive glucose lowering in type 2 diabetes. N Eng J Med 2008;358:2545-2559.

50. Malmberg K, Yusuf S, Gerstein HC, et al. Impact of diabetes on long term prognosis in patients with unstable Angina and non-Q wave myocardial infarction: Results of the OASIS registry. Circulation. 2000;102:1014.

51. Wilson CS, Futton RF, Gau GT, et al. CAD in diabetes and nondiabetes patients. A clinical and angiographic comparison. Clin cardiol. 1983;6:440446.

52. Abadie E, Masauet CN, Guionurd A, et al. Coronary angiography in diabetic and nondiabetic patients with ischemic heart disease. Diabetes Metab. 1983;9:53-57.

53. Mukund P. Srinivasan, Padmanabh K, et al. Factors associated with no apparent coronary artery disease in patients with type II diabetes mellitus for more than 10 years of duration: a case control study. Cardiovasc Diabetol. 2015;14:146.

54. Morgan KP, Kapur A, Beatt KJ, et al.. Anatomy of coronary disease in diabetic patients an explanation for poorer outcome after percutaneous coronary intervention and potential target for intervention. Heart. 2004;90:732-738.

55. Mukund P. Srinivasan, Padmanabh K, et al. Severity of coronary artery disease in type 2 diabetes mellitus: Does the timing matter? Indian Heart Journal. 2016;68:158-163. 